\title{
Models for assessing the impact of interregional interaction effects on the level of the EU countries' financial security
}

\author{
Lidiya Guryanova \\ S. Kuznets Kharkiv National University of Economics, \\ Economic Cybernetics Department \\ Kharkiv, Ukraine \\ guryanovalidiya@gmail.com
}

\author{
Elena Piskun \\ Sevastopol State University \\ Department of Finance and Credit \\ Sevastopol, Russia \\ lenapiskun@mail.ru
}

\author{
Stanislav Milevskiy \\ S. Kuznets Kharkiv National University of Economics, \\ Economic Cybernetics Department \\ Kharkiv, Ukraine \\ MilevskiySV@gmail.com
}

\begin{abstract}
In the conditions of increasing financial turbulence, permanently recurring crises, the problem of ensuring the macro-regions financial security is of particular importance. One of the directions of improving financial security systems is the development of a model basis for assessing, analyzing and forecasting the level of financial security, allowing early diagnosis of factors destabilizing the financial systems functioning and developing preventive strategies aimed at preventing financial crises and disasters. In the structure of such a model basis, models for assessing the impact of interregional interaction effects on the level of macro-regions financial security are highlighted. To build models, methods of factorial, canonical analysis, a taxonomic indicator of the level of development, methods of spatial econometrics, model of panel data were used. The models were built on the data of financial security indicators of the EU countries. The obtained results can be used by the financial stability departments to determine the most probable channels of infection by the crisis, to develop the adequate mechanisms for financial stabilization.
\end{abstract}

Key words - financial security, macro-region, modeling, interregional interaction, multidimensional analysis, spatial econometrics, panel data

\section{INTRODUCTION}

In the conditions of crisis trends in the development of macro-regions (countries) financial systems, the problem of ensuring financial security (FS) becomes especially important. Formation of a strategy to ensure financial security is impossible without analyzing a large amount of economic information in the dynamics. This predetermines the necessity to apply economic and mathematical methods and models for assessing and analyzing the current situation, developing scenarios for its future development, developing corrective preventive actions aimed at localizing the consequences of the financial security threats and their preventing, ensuring the stable functioning of financial systems.

The problem of economic and financial security was successfully handled by a galaxy of outstanding Russian and Ukrainian scientists, as well as a number of well-known foreign researchers. Significant achievements in developing a categorical basis for the mechanisms of economic and financial security system belong, in particular, to such Ukrainian scientists as O. Baranovskyi [1], M. Ermoshenko [2], S. Shkarlett [3] and others. Among Russian authors, it is needed to mention the fundamental works on the theoretical and methodological foundations of economic security of L. Abalkin [4], A. Bogdanov [5], V. Senchagov [6], others. Applied questions related to various aspects of the economic and financial security systems modeling are successfully dealt with by such scientists as G. Velikoivanenko, V. Geets, T. Klebanova, K. Kovalchuk, I. Lukyanenko, S. Marinchuk, I. Miroshnichenko, V. Ponomarenko, R. Rudenskyi, V. Khomyak, L. Chagovets, N. Chernova, A. Chernyak, G. Corsetti, R. Esprinoza, R.Glick, M. Pericoli, A. Prazad, M. Sbracia, , A. Roes [7-19].

Thus, the work of G. Velikoivanenko, I. Miroshnichenko touches upon the questions of modeling the macro-region investment security level on the basis of Kohonen selforganizing maps, methods of fuzzy logic theory [7]. The researches of V. Geets, T. Klebanova, V. Ponomarenko, N. Chernova are devoted to the formation of a model basis for the system of ensuring the economic and financial security for systems in different hierarchy levels, which includes models for the formation of a diagnostic indicators system of economic and financial security, a comprehensive assessment of the level of security, forecasting of threats and security level [8-9]. In the studies of K. Kovalchuk, S. Marinchuk [10], the task of forming effective "internal" zones of tax loyalty is touched upon, a model basis for selecting offshore zones for tax optimization is being developed. In R. Rudenskyi's work 
the structure of the model basis of the antisipative security management system is proposed [11]. In the work of A. Chernyak and V. Khomyak [12], the issues of modeling currency security as a dominant component of the FS, forecasting the crisis of the payments balance, and the choice of mechanisms for its prevention are considered. Various aspects of modeling the macro-region budget security were considered in the works of I. Lukyanenko, L. Guryanova, L. Chagovets [13-15]. Works of G. Corsetti, R. Esprinoza, R.Glick, M. Pericoli, A. Prazad, M. Sbracia, A. Roes touches up on the issues of infection crisis effect assessment [16-19].

It should be noted that, despite the unconditional effectiveness of the approaches proposed by the authors, the problems of modeling the assessment of the interregional interaction effects on the dynamics of the level of macroregions financial security are poorly studied. The development of such a model complex makes it possible to identify components that, at certain stages, contribute to an increase in the overall level of the macro-region financial security, or, on the contrary, create additional threats when external "shocks" are affected.

\section{RESEARCH METHODS}

The proposed methodical approach to the development of models for assessing the impact of interregional interaction effects on the dynamics of the macro-regions financial security level includes the following main blocks:

In block 1, the system of financial security indicators of the macro-region based on multidimensional analysis methods is substantiated.

The initial system of the macro-region financial security indicators is formed on the basis of expert analysis methods. In more detail expert analysis procedure is described in [20]. To assess the information content and filter the generated list of indicators, various methods can be used: methods based on the autoinformativity criteria; methods aimed at assessing the information content based on the cause-effect relationships analysis. The first group of methods makes it possible to evaluate the information significance of the indicators, to reveal hidden properties and patterns in large volumes of raw data, in the case when the structure of the input and output data sets is unknown. The advantage of the second group of methods is the possibility of reducing the dimensionality of the information space of features on the basis of analysis of the cause-effect relationships of a set of input and output indicators. The choice of the method is determined by complete or incomplete provision of information, sample size, the structure of a set of input and output indicators, and the availability of a training sample. Taking into account the restrictions on the data type, the structure of the indicator groups, a block diagram of the filter of the financial security indicators system is developed, a detailed description of which is given in $[14,21]$.

In block 2, a complex assessment of the financial security level and its structural components takes place. The construction of a system of integrated (on the whole system of indicators) and local (on separate components) integral estimates of the financial security level is caused by the diversity of indicators, which complicates their analysis and requires presentation in the form of a synthetic assessment, which is the result of a convolution of indicators reflecting the development of individual financial security subsystems. The block diagram of the formation of an integrated assessment of the financial security level is based on one of the methods for constructing a reference object - a taxonomic indicator of the development level $[14,20,21]$. The development level indicator is calculated by the formula: $d_{i}{ }^{*}=1-\frac{c_{i 0}}{c_{0}}$, where $c_{o}=\overline{c_{0}}+2 S_{0}, \quad \overline{c_{0}}=\frac{1}{n} \sum_{i=1}^{n} c_{i o}, \quad S_{o}=\frac{1}{n} \sqrt{\sum_{i=1}^{n}\left(c_{i 0}-\overline{c_{0}}\right)^{2}}$, $c_{i o}=\sqrt{\sum_{j=1}^{m}\left(Z_{i j}-Z_{o j}\right)^{2}}-$ the Euclidean distance between the points-units (states) and the point $P_{0}\left(z_{01}, z_{02}, \ldots, z_{0 m}\right)$, which is a development (benchmark). The basis for constructing a development reference object is the division of characteristics into stimulators and destimulators. The features that have a positive, stimulating effect on the financial security level are called stimulators, in contrast to the features-destimulators. The coordinates of the development reference object are defined as follows: $z_{0 j}=\left\{\begin{array}{c}\max _{i j}, \text { if } j \in I \\ i \\ \min z_{i j}, \text { if } j \notin I \\ i\end{array}\right.$, where $I-$ is stimulators array. Since the features have different dimensions, when forming the distance matrix $C=\left(d_{i o}\right), i=\overline{1, n}$ their standardization is carried out: $z_{i j}=\frac{x_{i j}-\overline{x_{j}}}{S_{j}}, S_{j}=\sqrt{\frac{\sum_{i=1}^{n}\left(x_{i j}-\bar{x}_{j}\right)^{2}}{n-1}}$. The values of the integral index vary from 0 to 1 . The closer the values of the integral index to 1 , the higher the macro-region financial security level.

In block 3, the development of panel data models taking into account the spatial lag is made, allowing to assess the influence of interregional interaction effects on the dynamics of the macro-regions financial security level.

The following versions of the panel data model were considered: the conventional panel data model $y_{i t}=\alpha+x_{i t}^{\prime} \beta+u_{i t}$, where $y_{i t}-$ the value of the financial security indicator for $i$ macro-region in time period $t, i=\overline{1, n}$, $t=\overline{1, T}, x_{\mathrm{it}}^{\prime}-$ vector of explanatory variables; $u_{i t}-$ disturbance for $i$ macro-region (object) in time period $t, \beta-$ model parameters; fixed-effect model $-y_{i t}=\mu_{i}+x_{i t}^{\prime} \beta+\varepsilon_{i t}$, where $\mu_{\mathrm{i}}, i=\overline{1, n}$ - fixed-effect; model with random effect $y_{i t}=\alpha+x_{i t}^{\prime} \beta+\mu_{s}+\varepsilon_{i t}$, where $\alpha-$ is general section.

When forming the variable spatial lag, the following approaches to determining the matrix of weights were used: 
matrix of boundary neighbors. It is assumed that the level of the financial security is affected only by nearby regions. The matrix of boundary neighbors is a binary matrix, where the element $w_{i j}$ is equal to one, if macro-region $i$ and $j(i \neq j)$ have a common boundary, and is equal to zero otherwise:

$$
w_{i j}=\left\{\begin{array}{l}
0, \text { if } i=j ; \\
1, \text { if macro-region } j \text { has a common border with macro-region } i ; \\
0, \text { if macro-region } j \text { has no common border with macro-region } i .
\end{array}\right.
$$

distance matrix. In this matrix of weights it is assumed that the spatial relationships outside the common boundaries are also significant:

$$
w_{i j}=\left\{\begin{array}{l}
0, \text { if } i=j \\
\frac{1}{d_{i j}^{\lambda}}, \text { if } d_{i j} \leq D(q) \\
0, \text { if } d_{i j}>D(q) .
\end{array}\right.
$$

where $d_{i j}$ - center-to-center distance; $D(q)$ - distance quantiles. The elements of such a matrix of spatial weights are analogs of the gravity coefficients.

The choice of the model specification was based on the tests of Fisher, Breusch-Pagan, Hausman.

As the initial data for approbation of the methodological approach proposed above, the data of the countries of the European Union and Ukraine, as a representative country of the countries with developing economies for 2006-2014, were considered. The choice of the analysis period is due to information security and methodological continuity of the calculation of financial security indicators, which are presented in open databases.

\section{RESULTS OF THE STUDY}

In accordance with the proposed methodological approach, the system of financial security integrated indicators was formed in the first two blocks in such areas of assessment as budget security, monetary market security, currency security, debt security, insurance security, stock market security, banking security, investment security. Data processing was carried out using the APP Statistica. The values of integrated indicators for one of the components - budgetary security - are shown in Fig. 1.

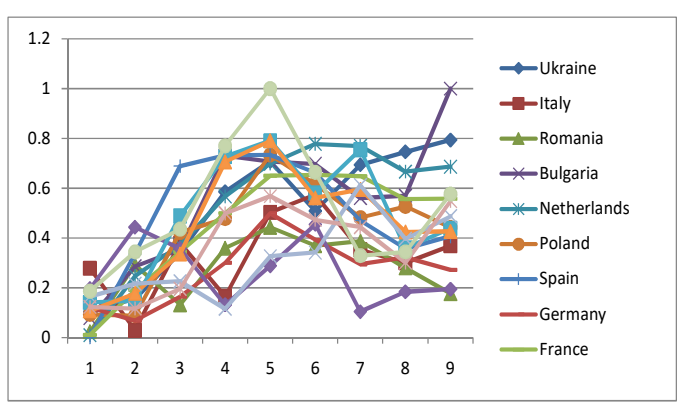

Fig. 1. Dynamics of the budgetary security integrated indicators level
As can be seen from Pic. 1, there is a positive trend in the financial security level of the EU countries. This trend is formed mainly at the expense of the countries of the "middle echelon" - France, Spain, Portugal, the Netherlands and Eastern European countries - Poland, the Czech Republic, Slovakia. It should be noted that such EU countries as Germany, Austria, Great Britain, Italy are characterized by a low level of budgetary security. Stable negative trends in the level of budgetary security are observed in Hungary and Romania. Similar results are obtained for the remaining components.

The developed system of the financial security level integrated indicators in the above components was considered as an information base for constructing panel data models with taking into account spatial lag (which allows estimating the influence of interregional interaction effects), which is the content of the third block of the methodological approach mentioned above. The results of estimating the models are given in Table. 1. Data was processed using APP EViews.

Table 1. Results of estimating panel data models taking into

\begin{tabular}{|c|c|c|}
\hline Integral index of FS & The model view & $\begin{array}{l}\text { Fisher } \\
\text { criterion } \\
\text { (F) }\end{array}$ \\
\hline Budget security & $x_{l}=c_{i}+0.19394 \cdot x_{l i, t-l}+0,185266 \cdot W x_{l i, t}+\varepsilon_{i t}$ & 254.3160 \\
\hline $\begin{array}{c}\text { Monetary market } \\
\text { security }\end{array}$ & $x_{2}=c_{i}+0.015 \cdot x_{2 i, t-l}+0,2268 \cdot W x_{2 i, t}+\varepsilon_{i t}$ & 948.53 \\
\hline Currency security & $x_{3}=c_{i}+0.122126 \cdot x_{3 i, t-1}+0,233409 \cdot W x_{3 i, t}+\varepsilon_{i t}$ & 345.3379 \\
\hline Debt security & $x_{4}=c_{i}+0.585148 \cdot x_{4 i, t-1}+0.080675 \cdot W x_{4 i, t}$ & 4156.326 \\
\hline Insurance security & $x_{5}=c_{i}+0.171273 \cdot x_{5 i, t-1}+0.222819 \cdot W x_{5 i, t}+\varepsilon_{i t}$ & 188.9355 \\
\hline $\begin{array}{l}\text { Stock market } \\
\text { security }\end{array}$ & $x_{6}=c_{i}+0.189583 \cdot x_{6 i, t-1}+0.220742 \cdot W x_{6 i, t}+\varepsilon_{i t}$ & 528.8670 \\
\hline Banking security & $x_{7}=c_{i}+0.399012 \cdot x_{7 i, t-1}+0.180699 \cdot W x_{7 i, t}+\varepsilon_{i t}$ & 1336.466 \\
\hline Investment security & $x_{8}=c_{i}+0.139919 \cdot x_{8 i, t-1}+0.249380 \cdot W x_{8 i, t}+\varepsilon_{i t}$ & 150.2138 \\
\hline
\end{tabular}
account spatial lag

The values of the determination coefficient (R-squared), varying from 0.647182 to 0.975818 ; values of the Fisher criterion (Tab. 1), Durbin-Watson statistics, varying from 1.742980 to 1.980162 , allow to draw a conclusion about the statistical significance and adequacy of models, the possibility of their application for further analysis.

It should be noted that in the models presented above, the coefficients of the endogenous spatial lag are statistically significant, which allows us to conclude that spatial clustering of countries is based on the financial security level. In Fig. 2 the values of the fixed effect of the budget security model are shown. 


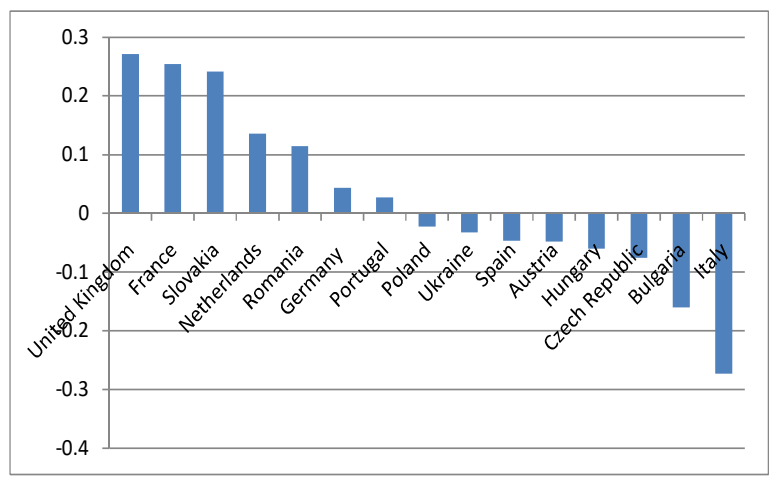

Fig. 2. Values of the budget security model fixed effect

The data shown in Fig. 2, allow us to conclude that the distribution of fixed effects is uneven with a pronounced decrease in values, which is characteristic for the fourth observation. The analysis of fixed effects provides an opportunity to identify countries that apply the most effective strategies for ensuring financial security. In particular, in the model of panel data of the budgetary security level, the countries that carry out the most effective management are the UK, France, Slovakia. The highest negative values of a fixed effect are observed in countries such as Italy and Bulgaria. Similar results were obtained for the remaining components of financial security. In particular, Fig. 3 shows the values of the fixed effects of the models of debt security and stock market security, which also speak of a significant asymmetry in the effectiveness of the mechanisms for managing the macroregions financial security.

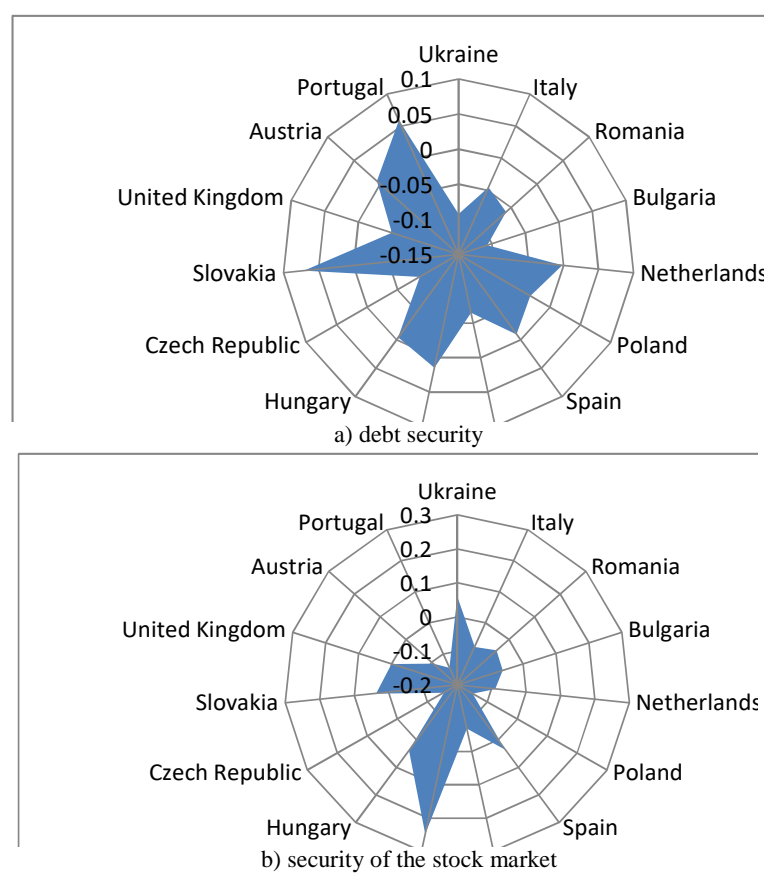

Fig. 3. The values of the fixed effects of the model

The percentage distribution of countries by the values of a fixed effect is given in Tab. 2.
Table 2. Percentage distribution of countries

\begin{tabular}{|c|c|c|c|c|}
\hline Types of security & Budgetary & Monetary & Currency & Debt \\
\hline Positive effect & $47 \%$ & $53 \%$ & $40 \%$ & $27 \%$ \\
\hline Negative effect & $53 \%$ & $47 \%$ & $60 \%$ & $73 \%$ \\
\hline Types of security & Insurance & Stock & Banking & Investment \\
\hline Positive effect & $33 \%$ & $33 \%$ & $33 \%$ & $13 \%$ \\
\hline Negative effect & $67 \%$ & $67 \%$ & $67 \%$ & $87 \%$ \\
\hline
\end{tabular}

As can be seen from Tab. 2, the most favorable situation is observed in the sphere of ensuring the monetary market security, budget security and currency security. Наиболеe уязвимыми являются сферы долговой и инвестиционной безопасности.

Analysis of the model coefficients with spatial lag variable (Tab. 1) allows us to conclude that the strongest positive effect on the system as a whole is observed in the sphere of debt security, banking security and budget security, which indicates the possibility of minimizing the system-wide costs associated with preventing a crisis in these subsystems. However, a comparative analysis of the marginal effect on the basis of the model without taking into account the spatial lag and model taking into account the spatial lag shows that the probability of local crises occurrence (crises in some EU countries) is significantly increased. A comparison of the average limiting effects is shown in Pic. 4.

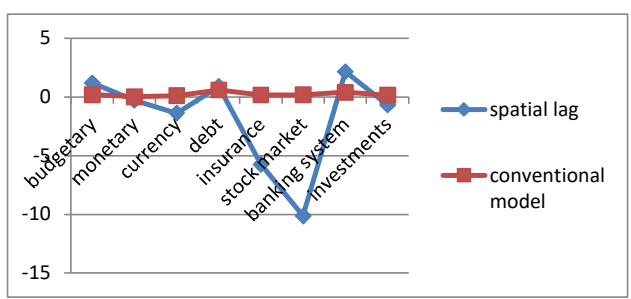

Fig. 4. Comparison of the limiting effects found on the basis of the conventional model and model, taking into account the spatial lag

As mentioned above, along with positive effects in the sphere of banking (average marginal effect is 2.1638), budgetary (1.1968), debt security (0.9025), there is a negative impact of spatial lag on the level of the stock market security $(-10.1407)$, insurance security -5.73$)$, currency $(-1.3723)$, investment (-0.6866), and monetary security (-0.29067). Thus, out of eight basic areas of financial security in five of them there is an increase in the probability of infection with the crisis. At the same time, the negative effect of the spatial lag impact in the dynamics is 4.27 times higher than the positive effect in the sphere of strengthening the banking, budgetary and debt security. Asymmetry in the effectiveness of local tools to neutralize threats (Tab. 2) leads to a resonant interaction of crises, primarily in the stock market security, insurance market security, currency security.

The percentage distribution of systematic risk between different areas of financial security and countries is shown in Fig. 5. 


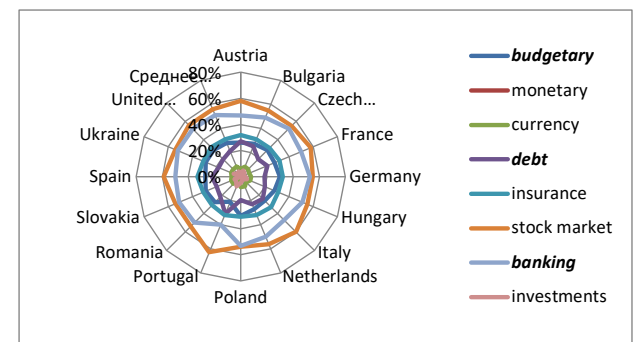

Fig. 5. Percentage distribution of systematic risk between different areas and countries

(note: spheres of positive influence are marked in italics)

The above analysis provides an opportunity to conclude that the mechanisms of ensuring financial security used in the Eurozone lead to an increase in the level of banking, budgetary and debt security by $51 \%, 28 \%$ and $21 \%$, respectively. However, at the same time there is a significant reduction in the level of stock security $(-56 \%)$, insurance security $(-31 \%)$, currency security $(-8 \%)$, investment security $(-4 \%)$, and monetary security $(-2 \%)$.

\section{CONCLUSIONS}

Thus, the studies carried out in the work allowed to draw the following conclusions:

the implementation of the model with spatial lag allowed to obtain statistically significant estimates for endogenous spatial lag and to conclude that there are positive effects of interregional interaction on the level of macro-regions financial security. Confirmation of positive influence speaks about the possibility of minimizing the costs associated with ensuring the banking, budgetary, debt security of the system as a whole;

crisis development tendencies are characteristic for such functional areas as the stock market security, insurance market, foreign exchange market, investment market, monetary security, which indicates a high sensitivity of financial security parameters to the relevant risk factors;

the identification of the mentioned above channels of infection with crises requires the use of adequate intraregional mechanisms to ensure financial security in these areas.

\section{REFERENCES}

Baranovskyi O. I. Financial Security in Ukraine. Methodology of evaluation and mechanism of support: Monograph - K: KNTEU.- 2004.- 759p.

Yermoshenko M. M. Financial security of the state: national interests, real threats, strategy of providing. - K.: Kyiv Nat. trade econ. Un-ty, 2001.- 309 p.

[3] Shkarlet S. M. Evolution of the category "safety" in the scientific and economic environment. / S. M. Shkarlet // Formation of market relations in Ukraine. - 2007. - №6. - P.6-12.
[4]

Abalkin L. I. Russia's economic security: threats and their reflection / L. I. Abalkin // Issues of economics. - 1994. - №12. - P. 4.

Bogdanov I. Ya. Economic Security of Russia: Theory research., Center for Sociology of Economics. - M., 2001. - 351 p.

[6]

Senchagov V. K. Economic Security of Russia. General course. - Moscow. : Business, $2005-896$ p.

[7]

Velikoivanenko G. I. Hierarchical logic-linguistic model of the estimation of investment potential of Ukraine taking into account risk / G. I. Velikoivanenko, Miroshnichenko I. V. // Culture of the peoples of the Black Sea region. — 2012. — № 231. - P. 14-18.

[8]

Modeling of economic security: state, region, enterprise: monograph / Heets V. M., Kizim M. O., Klebanova T. S., Chernyak O. I. and others; Ed. by Heets V. M. - Kh.: PH «INZHEK», 2006. $-240 \mathrm{p}$.

[9] Ponomarenko V. S. Economic security in the region: analysis, assessment, forecasting / V. S. Ponomarenko, T. S. Klebanova, N. L. Chernova - Kh.: PH «INZHEK», 2004. - 144 p.

[10]

Marinchuk S.G. Modeling strategies for using offshore zones for tax optimization by business entities. Abstract for obtaining a scientific degree of the candidate of economic sciences / S.G. Marinchuk. - Cherkasy, Eastern European University of Economics and Management, 2015. - 20 p.

[11] Rudenskyi R. A. Models of antisipative management for complex economic systems: author's abstract. dis for obtaining degree of doctor of economic sciences: spec. 08.00.11 - mathematical methods, models and information technologies in economics / R. A Rudenskyi - Donetsk, 2009. - 40p.

[12] Cherniak O. I. The balance of payments crisis: factors, indicators and methods of prevention / O. I. Cherniak, V. R. Khomiak // Economics and Forecasting. - 2011. - №4. - P. 27-37

[13]

Lukyanenko I. G. System modeling of indicators of the budgetary system of Ukraine / I. G. Lukyanenko. - Kyiv: 2004, Publishing House "Kyiv-Mohyla Academy", 242 p.

[14] Guryanova L. S. Modeling of balanced socio-economic development of regions: monograph / L. S. Guryanova. - Berdyansk: FOP Tkachuk O. V., 2013. - 406 p.

$[15]$

Chagovets L. A. Modeling of production-fiscal effects in the system of economic security of the state / Chagovets L. A. // Business-Inform. - 2013. - №10. - P. 130-135.

[16] Corsetti G. Some contagion, some interdependence: more pitfalls in test of financial contagion / G. Corsetti, M. Pericoli, M. Sbracia // J. International money and Finance. - 2005. - Vol. 24, №1. P 123-141.

[17] Esprinoza R. Nonperforming loans in the CCC banking system and their macroeconomic effects / R. Esprinoza, A. Prazad // IMF [Working Paper] № 10/224 - 2010 - P.32

[18] Fratzscher M. Asset prices, news shoks and current account / M. Fratzscher // European central bank [Working paper series] № 1561-0810.-2002.-P 38-51

[19] Glik R. Why are currency crisis contagious? / R.Glick, A.K. Roes // NBER [Working paper] № 6806. - 1997

[20] Adaptive methods in decision-making systems: monograph / Ed. by N. A. Kizim, T. S. Klebanova - Kh.: PH «INZHEK», 2007. -368 p.

[21] Guryanova L. S. Methods of choosing diagnostic indicators of financial security / L. S.Guryanova, V. V. Nepomnyashchiy // Business-Inform. - 2013. - № 4. - P. 377-381. 